\title{
CrimRxiv
}

\section{Review 2 of "Struggling to Make Good: The Dilemmas of Fatherhood for Formerly Incarcerated African American Men"}

Sean Wilson

Published on: Jun 21, 2021

DOI: 10.21428/cb6ab371.a86b7a7e

License: Creative Commons Attribution 4.0 International License (CC-BY 4.0). 
Vote: Publish pending minor changes

[For votes to count, referees must reasonably explain why they voted as they did. Thus, please explain your vote. If you voted to publish pending minor changes, specify each change, why it is needed, and, possibly, how it should/could be done.]

This article is well written and covers an important issue in society. However, missing is a thorough analysis of literature on Black male masculinity and fatherhood. Also missing is a thorough historical analysis of Black male masculinity and fatherhood. There is a large body of knowledge of Black masculinity and fatherhood that can strengthen this article. See "Fathers in the "hood": Insights from qualitative research on low-income African-American men by RL Jarrett, KM Roy, and LM Burtton. The findings section lacks a thorough analysis of race. Black males' experiences navigating fatherhood and reentry are unique and this article does not fully contextualize the unique lived experiences of Black formerly incarcerated fathers. The authors can improve this article by infusing more literature on Black male fatherhood and masculinity and fully contextualizing Black male fatherhood and reentry.

[Please put additional info below, as/if you see fit.]

Additional Info: Articles below will help to contextualizing Black male fatherhood https://journals.sagepub.com/doi/abs/10.1177/0192513x05275432

https://journals.sagepub.com/doi/abs/10.1177/019251399020004002 